\title{
Aspectos das fenofases reprodutiva e vegetativa de Campomanesia guazumifolia (Myrtaceae), na Região de Lages, Santa Catarina
}

\author{
Aspects of the Campomanesia guazumifolia (Myrtaceae) reproductive and vegetative \\ phenophases, in the Region of Lages, Santa Catarina
}

\section{Jacqueline Ortiz*, Luciana Magda de Oliveira, Anieli Cioato de Souza, Alexandra Cristina Schatz Sá, Gabriela Fernanda Souza e Bruno Jan Schramm Corrêa}

Universidade do Estado de Santa Catarina, Lages, SC, Brasil. *Autor para correspondência: ortizjak22@gmail.com.

\author{
Submissão: 10/03/2018 / Aceite: 01/03/2019
}

\begin{abstract}
RESUMO
Objetivou-se compreender os ciclos reprodutivo e vegetativo de Campomanesia guazumifolia (Cambess.) O. Berg., monitorando os eventos fenológicos e correlacionando com dados climáticos da região de estudo. Foram utilizados dois métodos de avaliação, o Índice de Atividade e o Índice de Intensidade (Índice de Fournier). A fenofase de floração ocorreu entre os meses de outubro a dezembro, e março a abril, com picos de intensidade de Fournier em novembro. A frutificação ocorreu de dezembro a abril, sendo que dezembro foi o mês de maior intensidade de frutos. A espécie apresentou período de maior queda foliar entre março e setembro, com pico de intensidade em agosto, e o brotamento com pico em setembro. Foi observada correlação positiva entre as variáveis climáticas de temperaturas máximas e mínimas mensais e a frutificação, e correlação negativa entre temperaturas máximas e médias mensais e a queda foliar.
\end{abstract}

PALAVRAS-CHAVE: índice de atividade, índice de Fournier, sete-capotes, variáveis climáticas.

\begin{abstract}
Our objective was to understand the $\mathrm{C}$. guazumifolia reproductive and vegetative cycles, monitoring its phenological events and correlating them to the climatic data of the studied region. Two evaluation methods were used, the activity index and the intensity index (Fournier index). The flowering phenophase occurred between the months of October and December, and from March to April, with Fournier peaks of intensity in November. The fruiting occurred from December to April, being December the most intense. The species presented the biggest foliar fall period between March and September, with intensity peak in August, and the budding presented a peak in September. It was observed a positive correlation between the climatic variables of maximum and minimum monthly temperatures to fruiting, and negative correlation between the climatic variables of maximum and medium monthly temperatures to foliar fall.
\end{abstract}

KEYWORDS: activity index, Fournier index, sete-capotes, climatic variables.

\section{INTRODUÇÃO}

Por meio da fenologia, são estudados eventos biológicos e suas relações com as mudanças climáticas sazonais, possibilitando a construção de um calendário fenológico (LIETH 1974). As observações destes eventos são importantes para prever épocas de reprodução, ciclos de crescimento vegetativo e características que podem auxiliar o manejo e cultivo, para realizar, por exemplo, o manuseio adequado e aprimoramento de programas de melhoramento, com cruzamentos direcionados e controlados (BREMENKAMP et al. 2016). O estudo integrado, incluindo a fenologia, pode também permitir compreender as estratégias reprodutivas de plantas e suas interações (OTÁROLA \& ROCCA 2014).

Os eventos fenológicos são classificados em fenofases, como as citadas por FOURNIER (1974). A ocorrência destes eventos normalmente está associada a fatores abióticos, principalmente aos climáticos, assim como aos fatores bióticos, como os genéticos. FRANKIE et al. (1974) citaram que ocorrem mudanças na fenologia em faixas geográficas diferentes, assim como alternâncias extremas de temperatura e/ou umidade, devendo haver estudos para as diferentes regiões, com pesquisas das diferenças e semelhanças 
entre as populações. Desta forma, para aprimorar os estudos de fenologia, foram criados métodos e correlações com o meio (BENCKE \& MORELLATTO 2002), como Índice de Atividade e Índice de Intensidade (Índice de Fournier) coletados das populações e relacionados às variáveis climáticas ocorrentes nas regiões de estudo.

Atualmente, as regiões tropicais e subtropicais têm recebido maior atenção e pesquisas relacionadas à fenologia das espécies, a exemplo dos trabalhos de CORDEIRO (2015), com estudos relacionados à Campomanesia phaea (O. Berg.) Landrum (Myrtaceae); MÜLLER \& SCHMITT (2017) com Guarea macrophylla Vahl (Meliaceae); RODRIGUES et al. (2017), com a fenologia de C. pubescens (DC.) O. Berg.; assim como trabalhos relacionados à fenologia, ecologia, restauração, conservação, uso e importância social (CORADIN et al. 2011, SOBRAL et al. 2017).

Na região Sul do Brasil, é encontrada grande diversidade florística, e a família Myrtaceae possui elevado número de espécies de interesse atual e potencial, com diferentes usos, entre eles, a utilização dos frutos como alimento pela fauna e pelos humanos (LORENZI 2008). Essa importância se estende ao gênero Campomanesia Ruiz et Pav., que no Brasil, são encontradas 44 espécies, sendo 12 no Estado de Santa Catarina (SOBRAL et al. 2015), dentre elas Campomanesia guazumifolia (Cambess.) O. Berg.

A espécie $C$. guazumifolia é popularmente conhecida como sete-capotes, sete-capas, capoteira, setecasacas. Árvore com porte mediano entre 8 a 12 metros de altura, raramente chegando a 30 metros de altura, e 20-30 cm de diâmetro, com casca descamante, com ramos pecíolos, parte abaxial das folhas, flores e frutos pubescentes ou velutinos. Folhas medianas ou grandes, oblongas, oval-oblongas até ovais, com contorno elíptico até ovado-oblongo, que é a forma mais comum no Brasil, nervuras salientes, flores com cinco a sete pétalas, ovários com oito ou mais lóculos, frutos velutinos e comestíveis (LEGRAND \& KLEIN 1977).

Para compreender o ciclo reprodutivo e vegetativo de C. guazumifolia, objetivou-se monitorar os eventos fenológicos de floração, frutificação, queda foliar e brotamento desta espécie, correlacionando com os dados climáticos da região de estudo.

\section{MATERIAL E MÉTODOS}

\section{Área de coleta}

O acompanhamento e a avaliação das fenofases de $C$. guazumifolia foram realizados em um pomar de espécies frutíferas nativas, situado no Centro de Ciências Agroveterinárias (CAV), da Universidade do Estado de Santa Catarina (Udesc), em Lages, Santa Catarina, com as seguintes coordenadas geográficas:

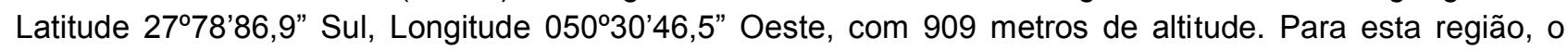
clima, de acordo com a classificação de Köppen, é mesotérmico úmido (Cfb), com precipitação anual de 1.809 milímetros e média de temperatura de $15,9{ }^{\circ} \mathrm{C}$, em 2016 (INMET 2017). Foram monitorados 10 indivíduos, com frequência semanal na fase reprodutiva e quinzenal na fase vegetativa. A coleta de dados foi realizada no período de junho de 2016 a maio de 2017.

\section{Avaliação da fenologia}

Para a avaliação da fenologia, foram consideradas as fenofases reprodutivas: floração: (1) botão floral, caracterizado pelo início da formação da estrutura floral; (2) antese, representada pela abertura dos botões florais; (3) senescência das flores ou queda das pétalas; frutificação: (4) frutos em desenvolvimento, fase entre a formação do fruto até o crescimento; (5) frutos imaturos, já crescidos; (6) frutos maduros, representada pela presença de frutos com coloração amarelo moderado à amarelo suave, segundo enciclopédia de cores online COLORHEXA (2017) característico da espécie; e vegetativas: (7) queda foliar, caracterizada pela presença de folhas amarelas na copa, queda das folhas com facilidade ao ventar, e folhas caídas sob a copa das árvores; e (8) brotamento, com presença de folhas jovens e brotações.

Foram aplicados dois métodos de análise aos dados fenológicos, o Índice de Atividade e o Índice de Intensidade ou Índice de Fournier. O Índice de Atividade avalia a presença e a ausência de determinado evento fenológico, e foi utilizado para estimar a sincronia da fenofase, indicando a proporção de indivíduos da população que está manifestando determinado evento fenológico (BENCKE \& MORELLATO 2002). O pico de determinada atividade foi considerado o momento em que o número máximo de indivíduos apresentaram a fenofase.

O Índice de Intensidade foi utilizado para estimar o percentual de intensidade das fenofases, metodologia proposta por FOURNIER (1974). Obedeceu-se a uma escala de 0 a 4, sendo 0 - ausência da fenofase; 1 - presença da fenofase com magnitude entre 1\% e $25 \% ; 2$ - presença da fenofase entre $26 \%$ e $50 \%$; 3 - presença da fenofase entre $51 \%$ e $75 \%$ e 4 - presença da fenofase entre $76 \%$ e $100 \%$. O índice foi calculado dividindo-se a soma dos valores de cada indivíduo em um dado mês pelo valor máximo 
possível (número de indivíduos multiplicados por quatro), e transformado em percentual.

\section{Dados climáticos}

Os dados climáticos foram fornecidos pelo Centro de Informações de Recursos Ambientais e de Hidrometeorologia de Santa Catarina, da Empresa de Pesquisa Agropecuária e Extensão Rural de Santa Catarina, (Epagri/Ciram), e pelo Banco de Dados Meteorológicos para Ensino e Pesquisa, do Instituto Nacional de Meteorologia (INMET 2017).

\section{Análise dos dados}

Os Índices de Atividade (sincronia) e de Intensidade foram correlacionados com as variáveis abióticas ambientais de temperatura mínima, média e máxima mensal $\left({ }^{\circ} \mathrm{C}\right)$, insolação (h.mês $\left.{ }^{-1}\right)$, pluviosidade mensal acumulada $(\mathrm{mm})$, e umidade relativa do ar (\%), por meio da Correlação de Spearman $\left(\mathrm{r}_{\mathrm{s}}\right)$, após o teste de normalidade de Shapiro-Wilk. Foi considerada correlação significativa ao nível de $5 \%(p \leq 0,05)$ e ao nível de $1 \%(p \leq 0,01)$. O software estatístico utilizado foi o SigmaPlot versão 13.0.

\section{RESULTADOS E DISCUSSÃO}

\section{Fenofases reprodutivas e vegetativas}

As fenofases reprodutivas de C. guazumifolia foram acompanhadas desde o surgimento dos botões florais até a queda dos frutos (Figura 1). A floração foi dividida pelas fenofases de botão floral, flores em antese e flores em senescência. Os botões florais de $C$. guazumifolia foram caracterizados por apresentarem coloração verde, pilosidade, formato oval, e encontraram-se sempre nas extremidades dos galhos, próximos aos pecíolos, com disposição oposta (Figura 1A).

As flores em antese apresentaram pétalas de cloração branca, com a borda recortada, vistosas, com numerosos estames e apenas um estigma ao centro (Figura 1B). E as flores em senescência apresentaram pétalas secas, e/ou queda destas estruturas, assim como queda dos estames, ficando apenas a estrutura feminina aderida ao perianto (Figura 1C).

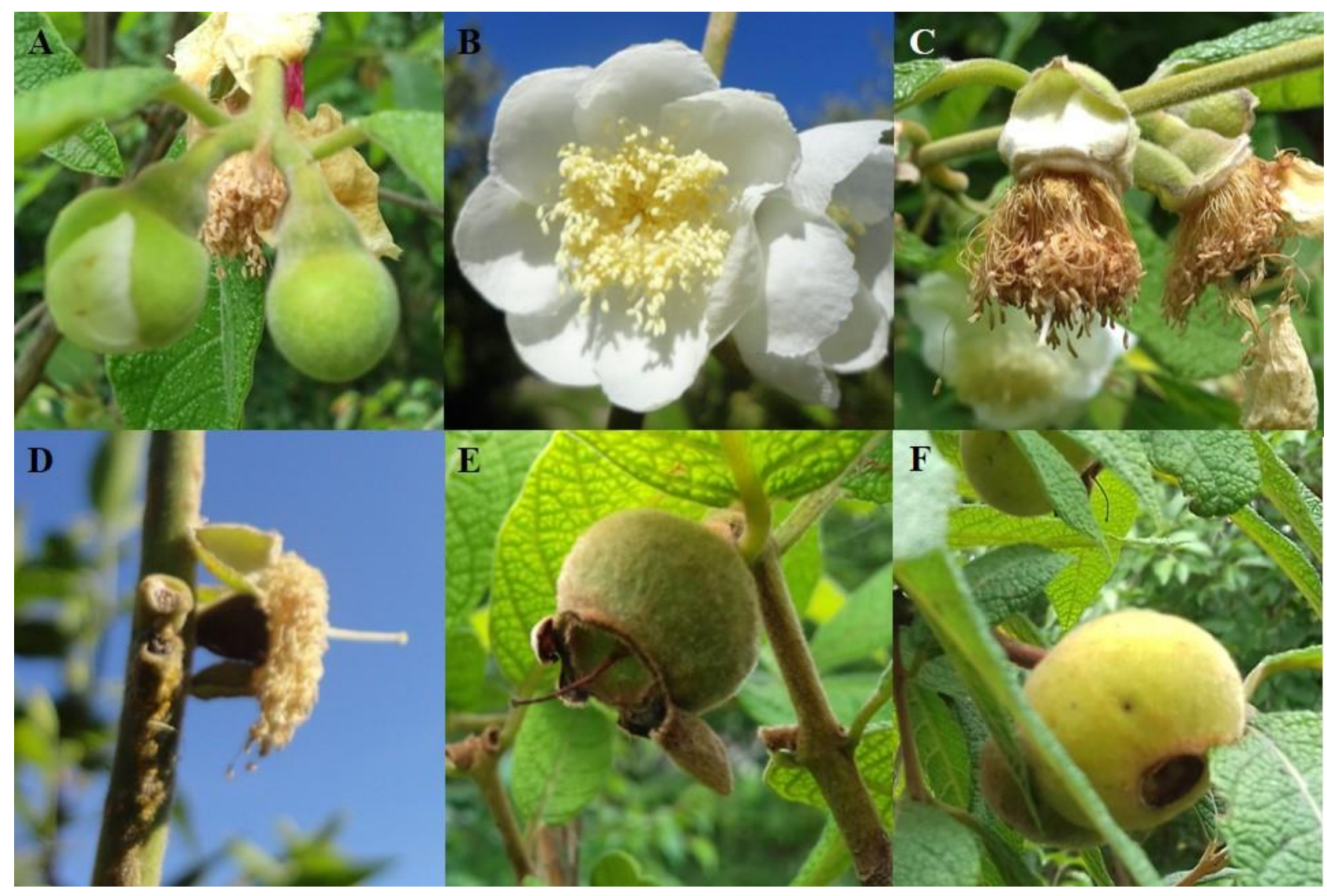

Figura 1. Fenofases de floração e frutificação de Campomanesia guazumifolia. A - presença de botões florais; B - flores em antese; C - flores em senescência; D -frutos em desenvolvimento; E - frutos imaturos; F - frutos maduros.

Figure 1. Flowering and fruiting phenophases of Campomanesia guazumifolia. A. presence of floral buds; $B$. flowers in anthesis; $C$. flowers in senescence; $D$. fruits in development; $E$. immature fruits; $F$. mature fruits. 
A frutificação foi dividida entre frutos em desenvolvimento e/ou crescimento, frutos verdes e frutos maduros. Durante o desenvolvimento do fruto, as estruturas das flores em senescência ainda estavam presentes, mas o fruto já apresentava crescimento (Figura 1D). Os frutos imaturos já possuíam tamanho próximo ao fruto maduro, com presença de pilosidade, e coloração verde (Figura 1E), com polpa consistente e rígida. Os frutos maduros observados apresentaram coloração amarelo moderado a amarelo suave, com pilosidade (Figura 1F), e passaram de textura endurecida a amolecida e permeável, facilitando a extração das sementes. Segundo GRESSLER (2005), as espécies da Família Myrtaceae possuem algumas características marcantes, como as flores vistosas, com inúmeros estames e de coloração clara, como apresenta C. guazumifolia.

As variáveis climáticas analisadas demonstraram que a insolação variou entre 98 a 203 horas mensais, ao longo do ano observado, sendo que a menor quantidade de horas ocorreu em dezembro de 2016 e a maior em maio de 2017 (Figura 2). A pluviosidade variou de 24,9 mm em junho de 2016, até 289,1 em maio de 2017, mostrando a irregularidade da pluviosidade neste período. A temperatura máxima mensal variou de $15,6^{\circ} \mathrm{C}$ a $28,3^{\circ} \mathrm{C}$, em junho e em fevereiro, respectivamente. As temperaturas médias ficaram entre $9,1^{\circ} \mathrm{C}$ e $21,8^{\circ} \mathrm{C}$, também para os meses de junho e fevereiro. As temperaturas mais baixas, entre junho e julho de 2016 , foram de $4,2^{\circ} \mathrm{C}$ e $5,7^{\circ} \mathrm{C}$, período entre outono e inverno no hemisfério sul. Já a umidade relativa apresentou pouca variação ao longo do período de acompanhamento e estudo, entre $78 \%$ e $88,7 \%$.
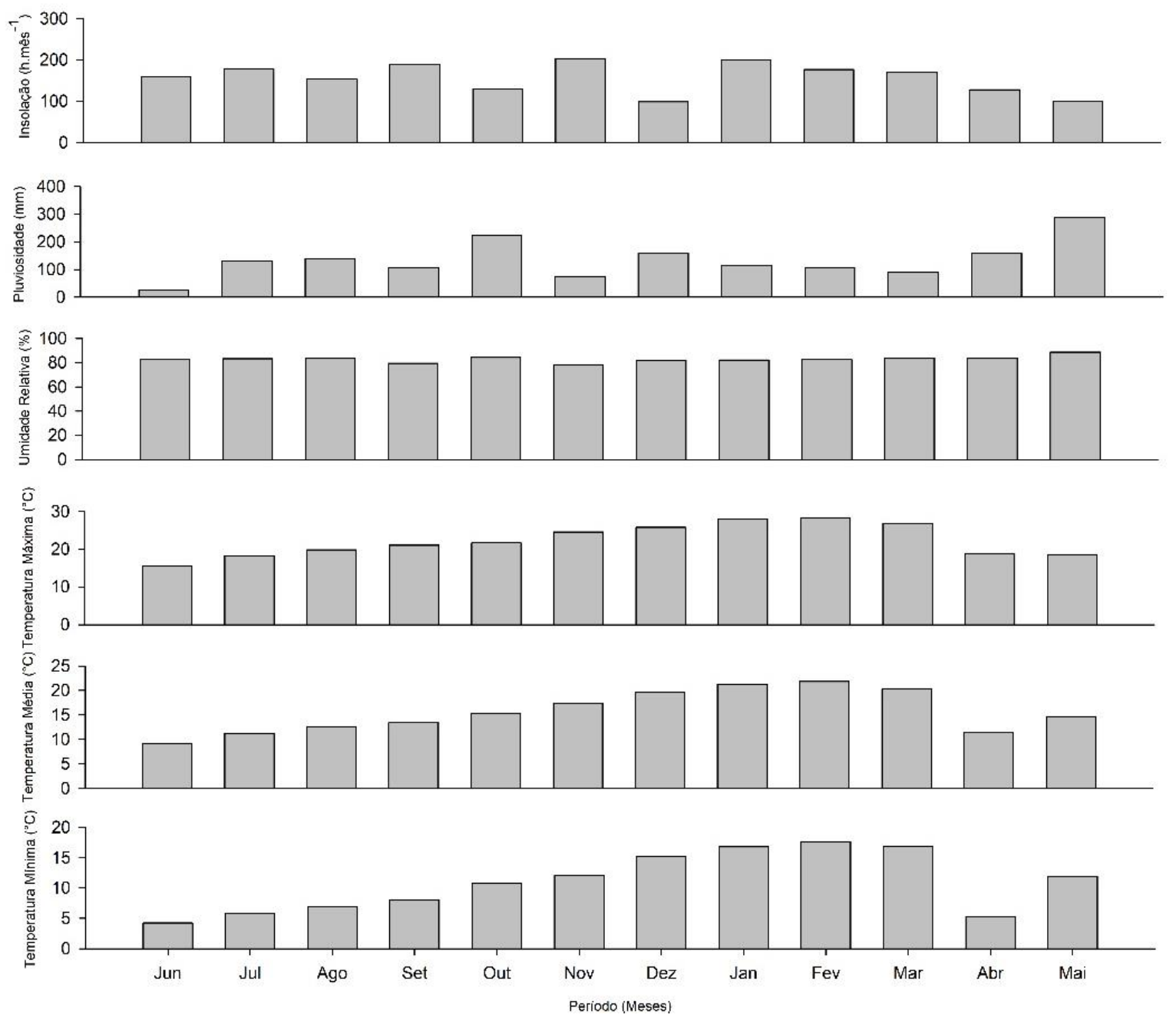

Figura 2. Variáveis climáticas observadas no período de junho de 2016 a maio de 2017, durante coleta de dados fenológicos de Campomanesia guazumifolia, em Lages, SC.

Figure 2. Climatic variables observed from June 2016 to May 2017, during phenological data collection of Campomanesia guazumifolia, in Lages, SC.

Para a fenofase de floração, foram observados dois picos de intensidade de Fournier, de outubro a dezembro de 2016 e em março a abril de 2017. A população observada chegou a possuir intensidade de $50,6 \%$ dos botões florais, flores em antese e em senescência no mês de novembro de 2016. Nos meses de 
março e abril de 2017, a floração reiniciou, mas de forma menos expressiva, com 5,7\% (Figura 3A). FERRERA et al. (2017) relacionaram o florescimento de espécies nativas do Rio grande do Sul com os meses com temperaturas do ar mais elevadas, maior intensidade de radiação solar incidente e dias mais longos. Este fato pode também ter gerado dois períodos de florescimento de C. guazumifolia, uma vez que as temperaturas em março e abril vinham oscilando e diminuindo de forma gradual, o que deve ter gerado baixos índices de florescimento.
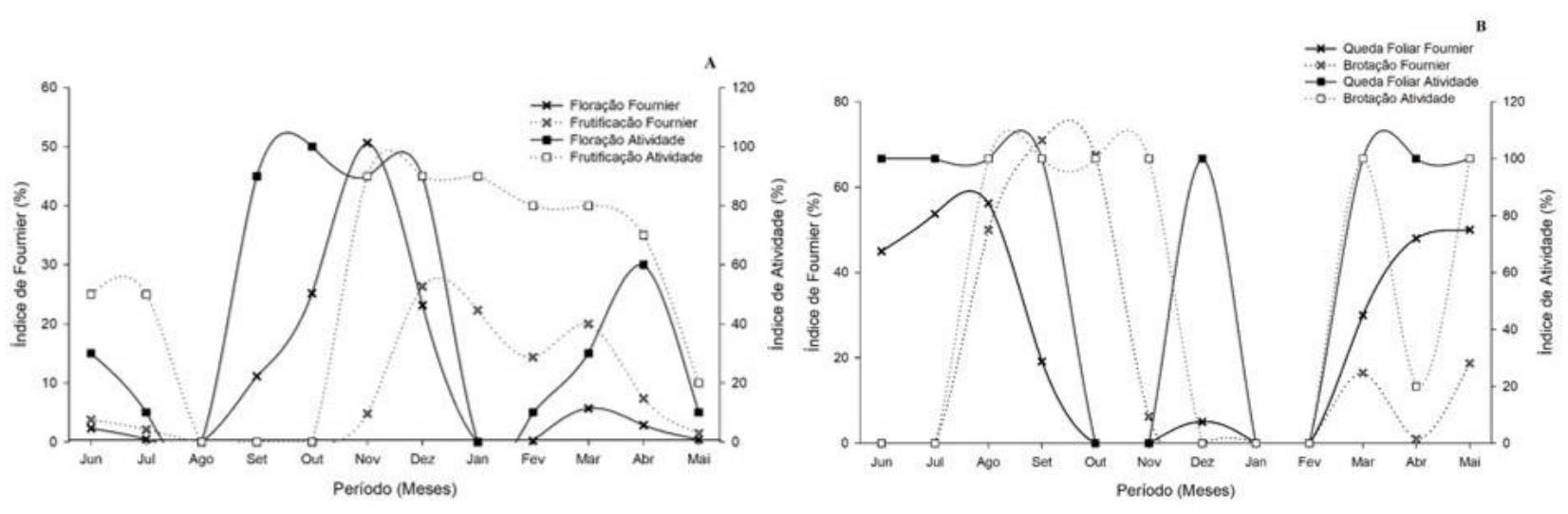

Figura 3. Índice de Intensidade e de Atividade nas fenofases de floração, frutificação, queda foliar e brotação de Campomanesia guazumifolia em Lages, SC. A - Fenofases reprodutivas; B Fenofases vegetativas.

Figure 3. Intensity and Activity rates in flowering, fruiting, leaf fall and sprouting phenophase of Campomanesia guazumifolia in Lages, SC. A. Reproductive phenophases; B. Vegetative phenophases.

$\mathrm{Na}$ fenofase de floração, a população apresentou Índice de Atividade de 90 a $100 \%$ entre o período de setembro a dezembro de 2016, com o auge da floração em outubro de 2016, com todos os indivíduos nesta fenofase, e no segundo pico de intensidade, em março e abril de 2017, o Índice de Atividade foi de 30 e $60 \%$ dos indivíduos com presença da fenofase, respectivamente.

Concomitante ao declínio da floração em dezembro, a frutificação aumentou e se estendeu até abril de 2017 , com intensidade de $7,3 \%$. O período de maior intensidade de frutificação foi em dezembro de 2016, com $26,3 \%$. O Índice de Atividade no período de frutificação foi elevado de novembro de 2016 a abril de 2017, com a população apresentando entre 70 a $90 \%$ de frutificação neste período. Os frutos maduros foram encontrados de janeiro a abril, cerca de 120 dias após a antese das flores.

CORDEIRO (2015) realizou estudos com a espécie Campomanesia phaea (O. Berg.) Landrum, em áreas naturais e cultivadas no Estado de São Paulo (Mogi das Cruzes e Bertioga), e identificou que sua floração iniciou em outubro e estendeu-se até janeiro, ou seja, ocorrendo apenas um período de floração no ano para ambos os locais, diferentemente de C. guazumifolia, em que ocorreram dois períodos no intervalo de um ano. Em relação à frutificação das espécies, ambas apresentaram um pico na produção e desenvolvimento dos frutos nos meses mais quentes do ano, entre dezembro e março. BAUER et al. (2014) estudaram a fenologia de Myrcia brasiliensis Kiaerski e Psidium catlleyanum Sabine, espécies também da família Myrtaceae, em ambiente natural no Rio Grande do Sul, e observaram período reprodutivo na primavera e verão, próximos ao encontrado em C. guazumifolia.

Para Campomanesia xathocarpa (Mart.) O. Berg., em um remanescente da Floresta Estacional Semidecidual no noroeste do Paraná, o pico de intensidade de floração foi de outubro a dezembro (AMORIM et al. 2010), apresentando períodos de reprodução semelhantes à espécie em estudo. Outro fator observado por AMORIM et al. (2010) foi um segundo período de reprodução, com menor expressividade de intensidade e de indivíduos. Já LUZ \& KRUPEK (2014) avaliaram a fenologia de C. xanthocarpa em Porto União, SC, em área de ocorrência natural, a qual iniciou o processo de floração em setembro seguindo até novembro, com o Índice de Atividade para os dois fenômenos fenológicos (formação de botões florais e flores) atingindo $100 \%$ no mês de outubro, semelhante a C. guazumifolia.

Para a fenologia vegetativa, as fenofases de brotamento e queda foliar de C. guazumifolia ocorreram simultaneamente e entre as fenofases reprodutivas. A fenofase de queda foliar aconteceu com maior intensidade nos períodos frios, em temperaturas mínimas entre $4,2^{\circ} \mathrm{C}$ e $7,9^{\circ} \mathrm{C}$, de junho a setembro. $\mathrm{O}$ pico de queda foliar foi observado em agosto de 2016, mas ocorreu de forma expressiva de junho a setembro de 
2016 e de março a maio de 2017 (Figura 3B).

Já para a fenofase de brotamento, a maior intensidade foi verificada de agosto a outubro de 2016, com pico em setembro, na qual foi encontrada intensidade de $71 \%$. Nos outros períodos observados ocorreu com menor expressividade. Com relação ao Índice de Atividade, a população apresentou sincronia, já que na maioria das vezes $100 \%$ dos indivíduos observados estavam na fenofase durante o mesmo período, tanto para a queda foliar, quanto para a brotação.

Para outras espécies da família Myrtaceae, como a M. brasiliensis, também ocorreu maior queda foliar no mês de agosto, na região de Novo Hamburgo, RS (BAUER et al. 2014), assemelhando-se com o comportamento de $C$. guazumifolia. Já $P$. catlleyanum não apresentou sazonalidade na perda e renovação das folhas, para a mesma região citada (BAUER et al. 2014).

Em relação ao brotamento e queda foliar, AMORIM et al. (2010) verificaram que a queda das folhas de C. xanthocarpa, no noroeste do Paraná, ocorreu de forma contínua e em todos os indivíduos, com maiores quedas nos meses de outubro a fevereiro. O mesmo ocorreu para a produção de folhas nos indivíduos analisados, cuja maior frequência se deu nos períodos mais quentes, que equivalem a dezembro e maio, para a região estudada (AMORIM et al. 2010).

O trabalho de LUZ \& KRUPEK (2014) com C. xanthocarpa apontam que os Índices de Atividade e de Intensidade das fenofases de brotamento e queda foliar exibiram valores crescentes durante o período de inverno e primavera, não sendo detectados picos significativos. BENCKE \& MORELLATO (2002) descreveram que o Índice de Atividade e o percentual de Intensidade de Fournier forneceram informações distintas e complementares, as quais facilitam a análise e interpretação do comportamento fenológico.

\section{Correlação entre fenologia e variáveis climáticas}

Ocorreu correlação positiva entre o Índice de Fournier e o Índice de Atividade com a temperatura máxima, para a fenofase de frutificação, que foi de $r_{s}=0,577, \quad(p=0,0446)$, e $r_{s}=0,573, \quad(p=0,0478)$, respectivamente. Para a frutificação e temperatura mínima também ocorreu correlação positiva, tanto para 0 Índice de Intensidade quanto para o de Atividade (Tabela 1).

Tabela 1. Correlação de Spearman $\left(r_{s}\right)$ entre as fenofases de floração e frutificação associadas aos Índices de Atividade e de Intensidade de Campomanesia guazumifolia e aos fatores climáticos.

Table 1. Spearman correlation (rs) between flowering and fruiting phenophases associated with Campomanesia guazumifolia Activity and Intensity rates and climatic factors.

\begin{tabular}{ccccc} 
& \multicolumn{2}{c}{ Índice de Intensidade } & \multicolumn{2}{c}{ Índice de Atividade } \\
\cline { 2 - 5 } & Floração & Frutificação & Floração & Frutificação \\
\hline \multirow{2}{*}{ Insolação } & $-0,0596$ & 0,0211 & $-0,146$ & 0,242 \\
& $\mathrm{p}=0,834$ & $\mathrm{p}=0,939$ & $\mathrm{p}=0,635$ & $\mathrm{p}=0,429$ \\
\hline \multirow{2}{*}{ Pluviosidade } & $-0,0596$ & $-0,254$ & 0,0285 & $-0,359$ \\
& $\mathrm{p}=0,834$ & $\mathrm{p}=0,415$ & $\mathrm{p}=0,921$ & $\mathrm{p}=0,243$ \\
\hline \multirow{2}{*}{ Umidade Relativa do ar } & $-0,207$ & $-0,31$ & $-0,167$ & $-0,488$ \\
& $\mathrm{p}=0,498$ & $\mathrm{p}=0,317$ & $\mathrm{p}=0,588$ & $\mathrm{p}=0,0998$ \\
\hline \multirow{2}{*}{ Temperatura Máxima } & 0,0456 & 0,577 & 0,0178 & 0,573 \\
& $\mathrm{p}=0,869$ & $\mathrm{p}=0,0446^{*}$ & $\mathrm{p}=0,939$ & $\mathrm{p}=0,0478^{*}$ \\
\hline \multirow{2}{*}{ Temperatura Média } & 0,00351 & 0,514 & $-0,0498$ & 0,53 \\
& $\mathrm{p}=0,974$ & $\mathrm{p}=0,0795$ & $\mathrm{p}=0,869$ & $\mathrm{p}=0,0705$ \\
\hline \multirow{2}{*}{ Temperatura Mínima } & $-0,0386$ & 0,69 & $-0,0961$ & 0,634 \\
& $\mathrm{p}=0,886$ & $\mathrm{p}=0,0113^{*}$ & $\mathrm{p}=0,749$ & $\mathrm{p}=0,0242^{*}$ \\
\hline
\end{tabular}

${ }^{*}$ significativo a $5 \%$.

Quando as temperaturas se elevaram, houve um aumento na sincronia da população em frutificação e a intensidade de ocorrência da fenofase. Em trabalho com $M$. brasiliensis e $P$. catlleyanum não foi verificada correlação significativa da fenofase de frutificação com as variáveis climáticas, e para floração 
ocorreu correlação significativa com a variável comprimento do dia (BAUER et al. 2014). Em trabalho com C. phaea, a intensidade de frutificação e a sincronia apresentaram correlação com a temperatura média mensal (CORDEIRO 2015).

Para $C$. xathocarpa, o pico de intensidade de floração ocorreu com os maiores índices pluviométricos médios (AMORIM et al. 2010). Para Acca sellowiana (O. Berg) Burret, que possui ampla ocorrência no mundo (nativa ou exótica), há variações na floração e frutificação devido à sua distribuição ocorrer nos trópicos e regiões subtropicais, com períodos de floração ainda incertos, relacionando estas variações com às variáveis de altitude, temperatura e pluviosidade das diferentes regiões (RAMíREZ \& KALLARACKAL 2017).

A fenologia de Eugenia dysenterica (Mart.) DC. demonstrou que o número de botões florais se correlacionou positivamente com a temperatura máxima, e negativamente com temperatura mínima e umidade relativa do ar, ou seja, quando as temperaturas máximas aumentam, aumentou também o número de botões florais, e a elevação das temperaturas mínimas e da umidade relativa do ar causaram diminuição dos botões florais. O mesmo ocorreu com a emissão de flores desta espécie, que teve correlação negativa com a temperatura mínima e a umidade relativa (CAMILO et al. 2013).

A fenologia vegetativa apresentou correlação entre temperatura máxima e média com queda foliar para os Índices de Intensidade e de Atividade. Para o Índice de Intensidade, a temperatura máxima e a média apresentaram correlação de $r_{s}=-0,747(p=0,00398)$, e $r_{s}=-0,733(p=0,00540)$ com a queda foliar (Tabela 2).

Tabela 2. Correlação de Spearman $\left(r_{s}\right)$ entre as fenofases de brotamento e queda foliar associadas aos Índices de Atividade e Intensidade de Campomanesia guazumifolia, com os fatores climáticos.

Table 2. Spearman correlation $\left(r_{s}\right)$ between budding phenophase and leaf fall associated with Campomanesia guazumifolia Activity and Intensity rates, with climatic factors.

\begin{tabular}{ccccc}
\cline { 2 - 5 } & \multicolumn{2}{c}{ Índice de Intensidade } & \multicolumn{2}{c}{ Índice de Atividade } \\
\cline { 2 - 5 } & Brotamento & Queda foliar & Brotamento & Queda foliar \\
\hline \multirow{2}{*}{ Insolação } & $-0,087$ & $-0,367$ & $-0,0311$ & $-0,461$ \\
& $\mathrm{p}=0,783$ & $\mathrm{p}=0,233$ & $\mathrm{p}=0,921$ & $\mathrm{p}=0,123$ \\
\hline \multirow{2}{*}{ Pluviosidade } & 0,297 & 0,267 & 0,183 & 0,154 \\
& $\mathrm{p}=0,329$ & $\mathrm{p}=0,389$ & $\mathrm{p}=0,557$ & $\mathrm{p}=0,619$ \\
\hline \multirow{2}{*}{ Umidade Relativa do ar } & 0,29 & 0,473 & 0,284 & 0,256 \\
& $\mathrm{p}=0,352$ & $\mathrm{p}=0,111$ & $\mathrm{p}=0,352$ & $\mathrm{p}=0,402$ \\
\hline \multirow{2}{*}{ Temperatura Máxima } & $-0,116$ & $-0,747$ & $-0,0584$ & $-0,615$ \\
& $\mathrm{p}=0,699$ & $\mathrm{p}=0,00398^{* *}$ & $\mathrm{p}=0,852$ & $\mathrm{p}=0,0308^{*}$ \\
\hline \multirow{2}{*}{ Temperatura Média } & $-0,138$ & $-0,733$ & $-0,0778$ & $-0,615$ \\
& $\mathrm{p}=0,651$ & $\mathrm{p}=0,00540^{* *}$ & $\mathrm{p}=0,800$ & $\mathrm{p}=0,0308^{*}$ \\
\hline \multirow{2}{*}{ Temperatura Mínima } & $-0,196$ & $-0,541$ & $-0,0622$ & $-0,41$ \\
& $\mathrm{p}=0,527$ & $\mathrm{p}=0,0663$ & $\mathrm{p}=0,834$ & $\mathrm{p}=0,173$ \\
\hline
\end{tabular}

**significativo a $1 \%$; " significativo a $5 \%$.

Para o Índice de Atividade, a temperatura máxima e a queda foliar apresentaram $r_{s}=-0,615$ $(p=0,00308)$, demonstrando correlação negativa. Assim como para a temperatura média e para a queda foliar, com $r_{s}=-0,615(p=0,00308)$. Desta forma, quando as temperaturas aumentam a queda foliar diminui em intensidade e na população avaliada.

Neste trabalho, não ocorreu correlação entre brotamento de C. guazumifolia e as variáveis climáticas avaliadas. Diferentemente do que foi citado por BAUER et al. (2014) para M. brasiliensis, na qual observaram que o brotamento ocorreu o ano todo em Novo Hamburgo, RS, e a queda foliar variou, com correlação positiva com a temperatura. Já para C. guazumifolia, os mesmos autores relataram que houve correlação negativa entre temperatura e queda foliar. Em estudo com a espécie Campomanesia 
adamantium (Cambess) O. Berg. em Minas Gerais, foi observada queda foliar quando a pluviosidade estava baixa, característica do local onde foi realizado o trabalho, além disso o déficit hídrico nessa região gera maior abscisão foliar (KUSTER et al. 2016).

Para a queda de folhas das espécies C. xanthocarpa, AMORIM et al. (2010) descreveram que esta fenofase foi contínua durante todo o período de estudo, em Paranavaí, PR. Todavia, em C. guazumifolia, esta queda foi maior em alguns períodos. Foi relatado também diferenças no período de intensidade da queda foliar, que em $C$. guazumifolia se deu entre os meses de junho e setembro, e em $C$. xanthocarpa foi de outubro a fevereiro. Acredita-se que essas diferenças entre as épocas do ano de ocorrência dos eventos fenológicos estejam relacionadas com o ambiente de inserção dos indivíduos, e às diferenças entre as espécies.

\section{CONCLUSÃO}

O monitoramento dos eventos fenológicos indicou que os ciclos reprodutivo e vegetativo de $C$. guazumifolia ocorrem com maior sincronia e intensidade entre os meses de novembro e dezembro, e agosto e setembro, respectivamente. As fenofases reprodutivas e vegetativas ocorrem juntas, entretanto os picos ocorrem em períodos diferentes.

Estas diferenças entre os períodos de ocorrência das fases reprodutiva e vegetativa foram correlacionadas com a temperatura. Temperaturas altas elevam a intensidade e a sincronia de frutificação, e temperaturas baixas elevam a queda foliar.

A fase reprodutiva possui grande heterogeneidade, com picos ao longo do ciclo, mas com a ocorrência de frutos maduros por longos períodos (janeiro a abril).

\section{REFERÊNCIAS}

AMORIM JS et al. 2010. Fenologia das espécies Campomanesia xanthocarpa O. Berg e Eugenia uniflora L. (Myrtaceae) no bosque municipal de Paranavaí, Paraná. Revista Eletrônica de Biologia 3: 84-98.

BAUER D et al. 2014. Fenologia de Ocotea pulchella, Myrcia brasiliensis e Psidium cattleyanum, em floresta semidecídua do Sul do Brasil. Floresta 44: 657-668.

BENCKE CSC \& MORELLATO LPC. 2002. Comparação de dois métodos de avaliação da fenologia de plantas, sua interpretação e representação. Revista Brasileira de Botânica 25: 269-275.

BREMENKAMP CA et al. 2016. Phenological characteristics of genotypes from cattley guava and guava trees submitted to fructification pruning. Revista Brasileira de Fruticultura 38: 727-733.

CAMILO YMV et al. 2013. Fenologia, produção e precocidade de plantas de Eugenia dysenterica visando melhoramento genético. Revista de Ciências Agrárias 36: 192-198.

COLORHEXA. 2017. Color encyclopedia: Information and conversion. Disponível em: <http://www.colorhexa.com/>. Acesso em: 17 fev. 2017.

CORADIN L et al. 2011. Espécies nativas da flora brasileira de valor econômico atual ou potencial: plantas para o futuro - Região Sul. Brasília: MMA. 934p.

CORDEIRO GD. 2015. Fenologia reprodutiva, polinização e voláteis florais do Cambuci (Campomanesia phaea (O. Berg) Landrum 1984- Myrtaceae). Tese (Doutorado em Entomologia). Ribeirão Preto: USP. 89p.

FERRERA TS et al. 2017. Fenologia de espécies nativas arbóreas na região central do estado do Rio Grande do Sul. Ciência Florestal 27: 753-766.

FOURNIER LA. 1974. Un método cuantitativo para la medición de características fenológicas em árboles. Turrialba 24: 422-423.

FRANKIE GW et al. 1974. Tropical Plant Phenology: Applications for Studies in Community Ecology. In: H. LIETH (ed.). Phenology and Seasonality Modeling. New York: Springer. p. 287-296.

GRESSLER E. 2005. Floração e frutificação de Myrtaceae de Floresta Atlântica: limitações ecológicas e filogenéticas. Dissertação (Mestrado em Ciências Biológicas). Rio Claro: USP. 102p.

INMET. 2017. Instituto Nacional de Meteorologia. Banco de Dados Meteorológicos para Ensino e Pesquisa (BDMEP). Disponível em: http://www.inmet.gov.br. Acesso em: 04 set. 2017.

KUSTER VC et al. 2016. Physiological and phenological vegetative responses of Campomanesia adamantium (Cambess) O. Berg (Myrtaceae) to the hydric seasonality of rupestrian fields. Revista Árvore 40: 973-981.

LEGRAND CD \& KLEIN RM. 1977. Britoa. In: LEGRAND CD \& KLEIN RM. Flora llustrada Catarinense: Mirtáceas. Itajaí: Raulino Reitz. p.630-634.

LIETH H. 1974. Purposes of a Phenology Book. In: LIETH H. (ed.) Phenology and Seasonality Modeling. Berlin: Springer 8: 3-19

LORENZI H. 2008. Árvores brasileiras: manual de identificação e cultivo de plantas arbóreas do Brasil. 5.ed. Nova Odessa: Instituto Plantarum. 384p.

LUZ IJ \& KRUPEK RA. 2014. Fenologia reprodutiva, biometria do fruto e semente de Campomanesia xanthocarpa 0.

Berg. (Myrtaceae). Estudos de Biologia Ambiente e Diversidade 36: 115-124.

MÜLLER A \& SCHMITT JL. 2017. Phenology of Guarea macrophylla Vahl (Meliaceae) in subtropical riparian forest in 
Southern Brazil. Brazilian Journal of Biology 78: 187-194.

OTÁROLA MF\& ROCCA MK. 2014. Flores no tempo: a floração como uma fase da fenologia reprodutiva. In: RECH AR et al. (orgs). Biologia da Polinização. Rio de Janeiro: Ceres Belchior. p.113-126.

RAMÍREZ F \& KALLARACKAL J. 2017. Feijoa [Acca sellowiana (O. Berg) Burret] pollination: A review. Scientia Horticulturae 226: 333-341.

RODRIGUES SS et al. 2017. Reprodutive biology and production of seeds and seedlings of Campomanesia pubescens (DC.) O. Berg. Journal of Seed Science 39: 272-279.

SOBRAL A et al. 2017. Conservation efforts based on local ecological knowledge: The role of social variables in identifying environmental indicators. Ecological Indicators 81: 171-181.

SOBRAL M et al. 2015. Myrtaceae; Lista de Espécies da Flora do Brasil. Jardim Botânico do Rio de Janeiro. Disponível em: http://floradobrasil.jbrj.gov.br/jabot/floradobrasil/FB10316. Acesso em: 31 out. 2015. 